些

\title{
Transmuraal team tegen oxycodongebruik
}

Thomas Knuijver, Janneke Pelser, Angelique van der Geest, Michel Terheggen

Hoewel de richtlijnen terughoudendheid adviseren, heeft het gebruik van oxycodon in Nederland een hoge vlucht genomen. Dat is zorgelijk, want opioïden zijn verslavend en je mag ze alleen voorschrijven als het echt niet anders kan. In de regio Arnhem heeft een transmuraal initiatief het gebruik van kortwerkend oxycodon in 3 jaar tijd sterk teruggedrongen door protocollen te stroomlijnen en nascholing te geven. Hopelijk kan het Arnhemse initiatief een voorbeeld zijn voor andere regio's.

Oxycodon is een veelgebruikte pijnstiller die, zoals alle opioiden, zeer verslavend is. Uit Amerikaans onderzoek blijkt dat oxycodon een opstap kan zijn naar heroïnegebruik. ${ }^{1}$ Bij langdurig gebruik kan opioïdgeïnduceerde hyperalgesie ontstaan, waarbij de pijn juist toeneemt. Zo kan een vicieuze cirkel ontstaan van toenemend gebruik. Niet voor niets adviseren richtlijnen om opioiden in principe niet voor te schrijven bij niet-oncologische (benigne) pijn. Maar richtlijnen worden niet altijd gevolgd. In 2003 werden in Nederland 22.366 recepten voor oxycodon uitgeschreven, in 2018 was dit aantal ruim vertwintigvoudigd tot $454.674 .{ }^{2,3}$ Ook huisartsen zijn vaker opioïden gaan voorschrijven, het meest voor klachten van het bewegingsapparaat. Daarbij gebruikt 30\% van de patiënten de pijnstiller langer dan 3 maanden. ${ }^{2}$ Voor een deel weerspiegelt dit een beter pijnstillend beleid, maar daar staat tegenover dat de incidentie van 'afhankelijkheid aan opioïden op recept' in de verslavingszorg tussen 2008 en 2015 is toegenomen van 3,1 naar 5,6 per 100.000 inwoners. En dat is een onderschatting, want lang niet alle patiënten laten zich verwijzen naar de verslavingszorg. Het aantal ziekenhuisopnames door opioïdintoxicaties verdrievoudigde tussen 2008 en 2017 van 2,5 naar 7,8 per 100.000 inwoners. Daarvan waren er 6,8 door opiö̈en op recept; het aandeel van illegale opioïden bleef gelijk.,5 In mei 2019 werd deze zorgelijke ontwikkeling aangekaart in het eerste-tweedelijnsoverleg van de regio Arnhem en omstreken en het Rijnstate Ziekenhuis. De regio heeft zo'n 450.000 inwoners en telt, naast meerdere vestigingen van Rijnstate, 114 huisartsenpraktijken met ruim 200 huisartsen, verenigd in 'Onze Huisartsen' (OH), en 42 apotheken die lid zijn van de Coöperatieve Apothekersvereniging Arnhem en omstreken (CAA). Naar aanleiding van dit overleg vormden een huisarts, een apotheker, een anesthesioloog/pijnspecialist en een

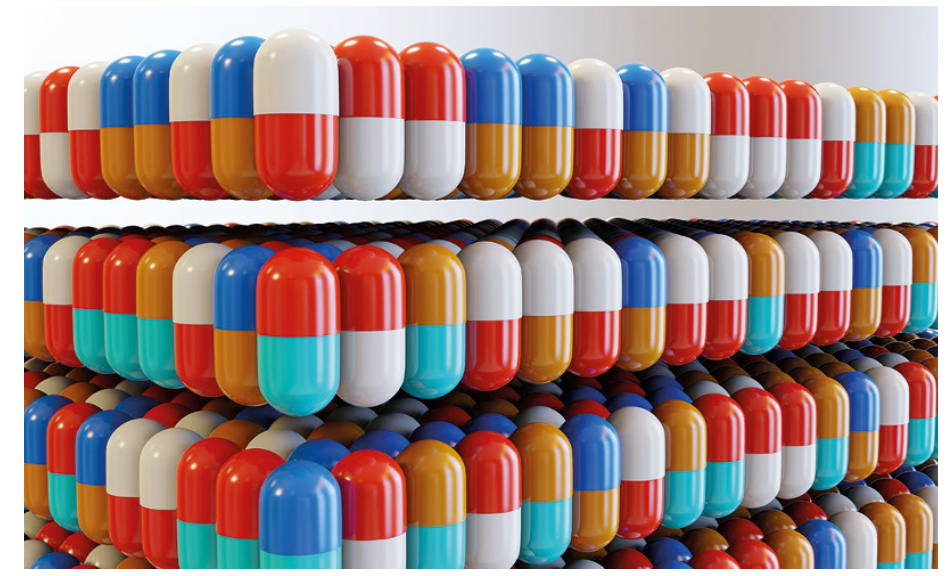

Het aantal recepten voor oxycodon is de laatste 15 jaar sterk gestegen, hoewel de richtlijnen adviseren hiermee terughoudend te zijn.

Foto: Shutterstock

verslavingsarts de transmurale commissie 'Verstandig omgaan met opioïden'. Hoofddoel was het aantal eerste recepten voor snel- en kortwerkende opioïden te verminderen, vanuit de gedachte dat de koppeling tussen gebruik en effect bij deze preparaten het sterkst is en daarmee de kans op afhankelijkheid het grootst. Een ander doel was duur en frequentie (antal gebruiksdagen) terug te dringen van het totale oxycodongebruik, en van opiaatgebruik in het algemeen. Rijnstate, $\mathrm{OH}$, CAA en de verslavingsintelling Iriszorg werden bestuurlijk (vanwege het delen van interne documenten) en op uitvoerend niveau op de hoogte gehouden van de voortgang.

\section{PROBLEEMINVENTARISATIE EN PROJECTBESCHRIJVING}

Een eerste inventarisatie leerde dat Rijnstate weliswaar over een postoperatief pijnbehandelingsprotocol beschikte, maar dat verschillende afdelingen op basis daarvan aparte protocollen gebruikten voor kortwerkend oxycodon. Verder bleek dat huisartsen, apothekers en hun assistenten grote behoefte hadden aan nascholing over opioïde pijnstillers, niet alleen om de problematiek te begrijpen maar ook om handvatten te krijgen hoe om te gaan met verslavingsgedrag in de spreekkamer. De commissie herzag in september en oktober 2019 alle protocollen voor acute en postoperatieve pijn van Rijnstate, zodat deze weer verwezen naar het basisprotocol. Aan dit ba- 


\section{DE KERN}

- Het aantal recepten voor oxycodon bij pijn is in 15 jaar vertwintigvoudigd.

- Ook huisartsen schrijven steeds vaker opioïden voor; 3 op de 10 patiënten gebruiken ze langer dan 3 maanden.

- Het stijgende gebruik van opioïde pijnstillers zorgt voor groeiende problemen met verslaving, intoxicaties en hyperalgesie.

- Het terugdringen van onnodig opioïdengebuik vereist een transmurale inspanning, waarbij pijnspecialisten, huisartsen en apothekers gezamenlijk de regionale pijnprotocollen doorlichten en gerichte nascholing verzorgen.

\section{TIPS EN TRICKS}

- Er is momenteel meer aandacht voor de risico's bij het gebruik van opioïden. Maak gebruik van die meewind!

- Een pijnspecialist die over de protocollen gaat, een betrokken huisarts en apotheker: meer is niet nodig. Consulteer de verslavingszorg voor patiënten die al afhankelijk zijn.

- Houd overleg simpel en klein. Digitaal overleggen is goed mogelijk.

- Presenteer een concreet plan voor een protocol, met afspraken en scholing in je eigen regio, waarmee mensen aan de slag kunnen.

- Rapporteer resultaten terug aan alle belanghebbenden, bestuurlijk en uitvoerend.

sisprotocol werd een kerndocument toegevoegd: 'Verstandig opiaten voorschrijven bij niet-oncologische pijn'. Dit document benoemt het risico op verslaving en opiaatgeïnduceerde hyperalgesie, geeft alternatieven en onderstreept het belang van verwachtingsmanagement en reëele behandoelen. Het basisprotocol adviseert alleen oxycodon met gereguleerde afgifte voor te schrijven, met een voorschrijfperiode van 1 week waarna evaluatie en zo nodig transmuraal overleg volgt. De commissie bracht het kerndocument en de verzamelde kennis met groot enthousiasme onder de aandacht van zo veel mogelijk collega's. In november 2019 werd het nieuwe protocol voor acute en postoperatieve pijn binnen Rijnstate uitgebreid gepresenteerd aan alle betrokken voorschrijvers en verpleegkundigen. In de daaropvolgende maanden volgden er ongeveer 15 FTO's waarin voorschrijvers, apothekers, verplegend personeel en dokters- en apothekersassistentes nascholing kregen. In januari 2020 hield een ervaringsdeskundige een indrukwekkend verhaal op een grote regionale nascholing voor huisartsen. En verder keerde het onderwerp steeds terug in nieuwsbrieven en lokale commissie- of ledenvergaderingen.

\section{DE CIJFERS}

De Stichting Farmaceutische Kengetallen (SFK) biedt apotheken de mogelijkheid om binnen specifieke samenwerkingsverbanden gegevens uit te wisselen. De CAA maakte voor de 39 aangesloten apotheken een groep aan waarin per kwartaal het aantal eerste uitgiften en gebruiksdagen kon worden bekeken van alle opioïden, voorgeschreven door alle specialisten en deelnemende huisartsen. Omdat de SFK geen indicaties onderscheidt, bevat de groep ook recepten voor oncologische pijn, een terechte indicatie voor kortwerkend oxycodon. De commissie vroeg daarnaast de ziekenhuisapotheek om eenmalig het totaal aantal gebruikte pillen te rapporteren, met als nulmeting het eerste kwartaal van 2019.

De [online tabel] laat per kwartaal het aantal eerste uitgiften en gebruiksdagen zien van zowel kort- als langwerkend oxycodon tussen begin 2019 en het vierde kwartaal van 2021 (gegevens over de andere opioïden zijn opvraagbaar bij de auteurs), en het aantal door de ziekenhuisapotheek uitgegeven tabletten in 2019 en 2020 . Het aantal eerste uitgiften van kortwerkend oxycodon door specialisten daalde van 688 aan het begin van 2019 naar 249 in het derde kwartaal van 2021, een daling van $63,8 \%$. Het aantal langwerkende preparaten steeg met $32 \%$ van 347 naar 461, maar toch daalde het totaal aantal eerste uitgiften vanuit het ziekenhuis met $31 \%$. Het aantal door huisartsen uitgeschreven eerste recepten voor kortwerkend oxycodon daalde van 1100 aan het begin van 2019 naar 426 in het derde kwartaal van 2021, een daling van $61,3 \%$, terwijl het aantal recepten voor langwerkend oxycodon licht steeg (1,5\%). In totaal daalde het aantal eerste uitgiften van kortwerkend oxycodon met $62,2 \%$; de totale reductie inclusief langwerkende preparaten was $37,1 \%$. Ook het aantal gebruiksdagen daalde aanzienlijk (67\%). De cijfers van de ziekenhuisapotheek geven hetzelfde beeld, waarbij opvalt dat de snijdende specialismen maar liefst $89,6 \%$ minder snelwerkend oxycodon gingen voorschrijven.

Voor de andere opioïden bleef het aantal uitgiften in het ziekenhuis min of meer constant (morfine $-12 \%$, fentanyl $+5 \%$, buprenorfine $+4 \%)$. Alleen tramadol werd vaker voorgeschreven (+290), wat de daling bij oxycodon (-325) compenseerde. Bij de huisartsen steeg het aantal eerste recepten voor morfine (+64) en fentanyl (+63), en vooral voor tramadol (+254), terwijl het aantal voor buprenorfine daalde (-9). Per saldo woog de toename $(+372)$ niet op tegen de daling bij oxycodon (-666).

\section{BESCHOUWING}

Ons project heeft binnen relatief korte tijd geleid tot een aanzienlijke daling van het gebruik van kortwerkend oxycodon: huisartsen en specialisten samen schreven $62 \%$ minder recepten uit. Het gebruik van langwerkend oxycodon steeg, maar per saldo werd binnen 11 kwartalen $38,1 \%$ minder oxycodon voorgeschreven. Internationaal onderzoek bevestigt dat een helder postoperatief pijnbeleid zowel de duur als het volume van het oxycodongebruik kan reduceren en ook dat nascholing geassocieerd is met een beter voorschrijfbeleid..$^{6-9}$ 
COVID-19 heeft waarschijnlijk bijgedragen aan de fluctuaties in de cijfers. In kwartaal 4 van 2020 en kwartaal 1 van 2021 waren er minder ziekenhuisopnames en operaties. Dit kan hebben bijgedragen aan de daling van het oxycodongebruik in het ziekenhuis, maar daar staat tegenover dat huisartsen vanwege de langere wachttijden wellicht vaker besloten oxycodon voor te schrijven. Gedurende het tweede en derde kwartaal van 2021 leverden de huisartsenpraktijken grotendeels reguliere zorg en werd in het ziekenhuis veel planbare zorg ingehaald. Verder konden we oxycodongebruik met een oncologische indicatie niet uitsluiten en verliep ook de oncologische zorg gedurende COVID-19 anders dan anders. Dit vertekent het beeld verder.

Volgens de GIPdatabank daalde het totaal aantal oxycodongebruikers in Nederland in 2019 met 7,9\% en in 2020 met $8,3 \% .{ }^{3}$ De cijfers voor 2021 zijn nog niet bekend, misschien is er inderdaad een dalende trend. Onze cijfers zijn niet direct vergelijkbaar, want wij keken naar het aantal eerste recepten en niet naar het aantal gebruikers, maar het is goed mogelijk dat onze interventie de toch al ingezette daling een extra duw heeft gegeven. De landelijke daling wijst op een groeiend bewustzijn over de gevaren van opioïden en dat zal zeker hebben bijgedragen aan een gunstig klimaat voor onze interventie.

Landelijk is het gebruik van diclofenac en ibuprofen sterk afgenomen na 2008, toen de groei van oxycodon begon, en is de uitgifte van naproxen meer gaan fluctueren. ${ }^{3}$ Dat deze ontwikkeling doorgaat nu het oxycodongebruik afneemt, bewijst dat er op 'pijnstillergebied' meer veranderingen optreden. Het nuanceert ook de 'vlucht naar tramadol' die wij waarnamen.

Onze interventie had tot doel de uitgifte van kortwerkend oxycodon terug te dringen. In het ziekenhuis leidde dit tot een stijging in de uitgifte van langwerkend oxycodon. De literatuur is niet eenduidig over de vraag of dit een wenselijke verschuiving is, maar we nemen aan dat de algehele reductie in oxycodongebruik in elk geval minder blootstelling en dus minder risico betekent. Een andere vraag is of het terugdringen van opioïden niet strijdig is met het streven naar adequate pijnstilling. Wij denken dat het goed kan, zolang men de richtlijnen maar volgt. Pijnstilling staat nog steeds centraal in het protocol en in de werkafspraken, en er is een duidelijke verschuiving naar tramadol conform de pijnladder. We hebben echter niet gekeken naar de exacte equivalentie van pijnstillers en naar de ervaringen van patiënten. Een herhaling van onze interventie, liefst met een controlegroep en tegen het licht van landelijke cijfers, zou een beter beeld kunnen geven van het werkelijke effect op de pijnstilling.

Aan de opzet van onze interventie valt veel te verbeteren, maar we hadden als commissie het voordeel dat we ons niet hoefden te bekommeren over commitment vooraf, financiering en onderzoeksopzet. Daardoor konden we snel en naar eigen inzicht handelen. Op de lange termijn moet blijken in hoeverre dat heeft geleid tot blijvende resultaten.

\section{VERVOLGSTAPPEN}

Pijncentrum Rijnstate organiseert een speciaal spreekuur voor patiënten met chronische pijn die problemen ervaren door opiödengebruik, maar die te 'licht' zijn voor een verslavingsarts. Ook een overleglijn voor eerstelijnszorgverleners staat in de steigers. Essentieel in deze aanpak is de transmurale, multidisciplinaire benadering. Ook landelijk groeit de aandacht voor patiënten die al verslaafd zijn en komen er meer behandelmogelijkheden. Men zal dus samenwerking moeten zoeken met verslavingszorginstellingen die specifieke kennis hebben van opiaatafhankelijkheid bij pijnpatiënten.

De neiging om in oude (voorschrijf)patronen terug te vallen, zal altijd aanwezig blijven, zeker waar het om verslaving gaat. Het veranderen van zulke patronen vergt een langdurige investering. Een belangrijke hobbel daarbij is dat het onderwerp 'opioïden' op de nascholingsagenda moet wedijveren met andere onderwerpen, zoals COVID. De beste garantie voor de lange termijn bieden landelijke initiatieven om het gebruik van opioïden terug te dringen, zoals die van Zorginstituut Nederland en de KNMG. Zulke initiatieven liggen echter buiten de reikwijdte van onze commissie.

De kracht van onze interventie school in de transmurale samenwerking, de eenduidige en overzichtelijke afspraken en vooral in de doeltreffende 'niet lullen maar poetsen'-aanpak. Wij denken dat we daarmee de blootstelling aan oxycodon en dus het risico op verslaving hebben weten te reduceren. We roepen andere lokale en regionale samenwerkingsverbanden dan ook op om vergelijkbare initiatieven te starten op basis van de nieuwe landelijke richtlijnen. De gebruikte documenten zijn op te vragen bij de auteurs..

\section{LITERATUUR}

De literatuur en gerelateerde content staan bij dit artikel op www.henw.org.

Knuijver TG, Pelser J, Van der Geest A, Terheggen MA. Transmuraal team tegen oxycodongebruik. Huisarts Wet 2022;65[4]:35-7. DOl:10.1007/s12445-022-1419-9.

Radboudumc, Nijmegen: T.G. Knuijver, verslavingsarts, thomas.knuijver@radboudumc.nl. Huisartsenpraktijk Rozet, Westervoort: J. Pelser, huisarts. Apotheek Duiven: A. van der Geest, apotheker. Pijncentrum Rijnstate, Velp: M.A.M.B. Terheggen, anesthesioloog. Mogelijke belangenverstrengeling: Thomas Knuijver ontving in 2018 van Grunenthal een eenmalige sprekersvergoeding voor een avond over opiaatreductie; Michel Terheggen is gehuwd met een employé van Sanofi Genzyme. 